\section{BETTING SHOP ROBBERIES: REDUCING THE RISK TO RETAIL STAFF}

JAMES BANKS, NICHOLAS ADDIS, AND JAIME WATERS

\section{INTRODUCTION}

I

$\mathrm{n}$ Britain, the perceived increase in and clustering of licensed betting offices (LBOs) continue to cause much public and political consternation at both a local and a national level. There are currently in the region of 8,700 betting shops in operation, representing a significant decline from their heyday in 1970s when they totaled in excess of $16,000 .{ }^{1}$ Despite this long-term decrease in shop numbers, ${ }^{2}$ LBOs have never been more prominent in British towns and cities. Reflecting gambling's ascendance to a mainstream leisure pursuit, LBOs have migrated from back street to side street to high street. ${ }^{3}$ Today, rare is the city center that is not adorned with the colors of a William Hill, Coral, Ladbrokes, Betfred, or Paddy Power. ${ }^{4}$ But although betting shops have undergone significant cosmetic improvements to both their interiors and exteriors, it appears that, for some, the drab image of the illegal backstreet bookie has never quite been shaken off. ${ }^{5}$ Indeed, betting shops frequently feature in criticisms of the proliferation and propinquity of a broad array of undesirable establishments - fast food takeaways, lap dancing clubs, payday loan businesses, pawn shops, and bargain booze off licenses - that "appear to trigger forms of repulsion among the middle class because they are seen to embody an excessive or ill-mannered working-class identity that is 'out of place' in the gentrifying city." In particular, LBOs are often perceived and portrayed as predatory and opportunistic organizations that drive out legitimate businesses and exploit and damage local communities. $^{7}$

Such concerns have certainly been heightened by the marked growth in fixed-odds betting terminals (FOBTs) which are sited on such premises. Although FOBTs were introduced in 2002, the changes to the gambling landscape wrought by the passage of the Gambling Act 2005 has seen the rapid expansion of FOBTs, with in the region of 35,000 machines in operation in 2013-14. ${ }^{8}$ Under the act, up to four machines may be located at an individual LBO and, with the demand criterion ${ }^{9}$ abolished, local licensing authorities' ability to prevent the opening of new betting shops has been severely constrained. FOBTs have become integral to the viability and sustainability of the modern day betting shop,
Dr. James Banks is a reader in the Department of Law and Criminology at Sheffield Hallam University in Sheffield, United Kingdom.

Dr. Nicholas Addis is a lecturer in the Department of Law and Criminology at Sheffield Hallam University in Sheffield, United Kingdom.

Dr. Jaime Waters is a senior lecturer in the Department of Law and Criminology at Sheffield Hallam University in Sheffield, United Kingdom.

Keywords: crime, robbery, gambling, violence, licensed betting offices

DOI: $10.1089 /$ glr2.2020.0019 (C) Mary Ann Liebert, Inc.

${ }^{1}$ Phillip W. S. Newall, How Bookies Make Your Money, 10(3) Judgment And Decision MAKING 225 (2015).

${ }^{2}$ A study by Deloitte found that there has been a recent growth in betting shop numbers, although the number of shops compared to the historic peak is overstated. By contrast, the Association of British Bookmakers claim that 400 betting shops closed within the last 18 months. Deloitte, The Changing Face of Retail: Where Did All the Shops Go? (2014), https://www2.deloitte.com/content/dam/Deloitte/ uk/Documents/consumer-business/the-changing-face-of-retail-where-did-all-theshops-go.pdf (last visited July 21, 2020); How Many Betting Shops Are There? Are Their Numbers Growing?, Association of British BooKMAKers (2018), http:// abb.uk.com/how-many-betting-shops-are-there-are-their-numbers-growing/ (last visited July 21, 2020).
${ }^{3}$ Peter Jones, Colin M. Clarke-Hill, and David Hillier, Viewpoint: Back Street to Side Street to High Street to E-street: Sporting Betting on the Internet, 28(6) INT'L J. Retail \& Distribution Mgmt. 222 (2000).

${ }^{4}$ Tom Lamont, The Big Gamble: The Dangerous World of British Betting Shops, THE GUARDIAN (May 31, 2016), https://www.theguardian.com/business/2016/may/ 31/big-gamble-dangerous-british-betting-shops.

${ }^{5}$ James Banks and David Moxon, UIEGA and the Rise and Rise of Gaming and Gambling in the UK, CRIMETALK (Jan. 30, 2012), https://www.crimetalk.org.uk/ index.php?option=com content\&view=article\&id=622:uigea-gaming-and-gamblinguk\&catid=38:frontpage-articles\&Itemid=41 (last visited July 21, 2020).

${ }^{6}$ Phil Hubbard, The Battle for the High Street: Retail Gentrification, Class and DisGust (Palgrave, 2017).

${ }^{7}$ Neli Demeriva, Rise in Betting Shops Fuels Crime Fears, POLITICs.co.uk (Nov. 6, 2014), http://www.politics.co.uk/opinion-formers/economic-social-research-councilesrc/article/esrc-rise-in-betting-shops-fuels-crime-fears (last accessed July 21, 2020).

${ }^{8}$ Gambling Commission, Industry Statistics: April 2011 to March 2015 (Updated to Include October 2014 to September 2015) (2016), http://www. gamblingcommission.gov.uk/Gambling-data-analysis/statistics/Industry-statistics. aspx (last accessed July 21, 2020).

${ }^{9}$ The so called "demand test" required potential licensees to demonstrate that their establishment would fulfill unmet demand for gambling services. 
generating in the region of $£ 900$ per machine per week and approximately $£ 1.5$ billion per year. ${ }^{10}$ Disconcertingly, this has led to an increase and clustering of LBOs in areas of high socio-economic deprivation where operators are able to extract revenues from already marginalized communities. ${ }^{11}$

Local councillors, anti-gambling campaigners, and some sections of the media continue to argue that LBOs housing FOBTs have a severe detrimental impact on the communities in which they are located. Alongside arguments that such operations increase problem gambling, a second objection to the licensing of new betting shops is that they lead to rises in crime and disorder in and around their premises. Yet empirical evidence to support this supposition is scant. ${ }^{12}$ Instead, it appears that news articles attributing violent offending, money laundering, robbery, and vandalism to the proliferation and clustering of LBOs housing FOBTs fuels public perceptions that they cause crime and antisocial behavior. Whilst much of this reporting is anecdotal, data derived from a freedom of information request to the Metropolitan Police does illustrate that "incidents" at LBOs in London boroughs requiring police attention rose from 7,436 in 2013 to 9,083 in January-September $2014 .{ }^{13}$ The notable number of incidents at such premises undoubtedly has implications for both betting shop employees and clientele.

It is in this context that betting shop robberies continue to receive significant national and local media attention. This article does not seek to contribute to the debate as to whether or not LBOs or their location increase crime and disorder in the communities in which they reside. Rather we seek to utilize news reports of betting shop robberies to consider how gambling operators may better institute practices that reduce the risks posed to staff who work in such environments. By way of introduction, the article outlines routine activity theory and optimal foraging theory as a framework through which to make sense of robberies committed against betting shops. We illustrate that although such perspectives have been applied to casino crimes in the U.S., there has been little attempt to utilize these theories when examining gambling-related crime in the UK. Discussion develops to examine the key features of betting shop robberies reported across national and local media throughout 2016 and 2017, before considering the implications of our findings for worker safety.

\section{GAMBLING ESTABLISHMENTS AND CRIME}

Environmental criminology presents a suitable theoretical framework through which to examine betting shop robberies. Pertinently, routine activity theory (RAT), denotes that for an offense to take place, three components of a crime situation must be present: a motivated offender, a suitable target, and the absence of a "capable guardian." "14 The importance of guardianship in deterring criminal behavior is echoed in another environmental approach to understanding criminal behavior: "optimal forager" theory. Originating from studies of animal foraging behavior, ${ }^{15}$ optimal forager theory, when applied to crime, stresses that offenders will seek to maximize reward, minimize risk of detection, and minimize time and effort taken in the committal of an offense. ${ }^{16}$

Much of the research exploring the connections between gambling establishments and crime has focused on casinos located in North America. In accordance with RAT, Johnson and Ratcliffe ${ }^{17}$ suggest that the characteristics of casinos are conducive to offending behavior. First, the availability of (often free) alcohol in casinos can present opportunity for, and committal of, crime and victimization. For example, alcohol may reduce the inhibitions of potential offenders. As a consequence, patrons who become frustrated over losing money may be more likely to engage in aggressive or violent behavior towards staff

\footnotetext{
${ }^{10}$ Linda Hancock and James Orford, FOBTs: Beyond Regulation?, New Statesman, May 16-22, 2014, at 10.

${ }^{11}$ Heather Wardle, Exploring Area-Based Vulnerability to Gambling-Related Harm: Who Is Vulnerable? Findings from a Quick Scoping Review (Gambling \& Place Research Hub, Geofutures, 2015).

${ }^{12}$ Mark D. Griffiths, Betting Shops and Crime: Is There a Relationship?, INTERNET J. Criminology (2011); James Banks, Gambling Crime and Society (Palgrave, 2017).

${ }^{13}$ Banks, supra note 12 .
}

\footnotetext{
${ }^{14}$ Lawrence E. Cohen and Marcus Felson, Social Change and Crime Rate Trends: A Routine Activity Approach, 44(4) Aм. Socio. Rev. 588 (1979).

${ }^{15}$ John R. Krebs and Nicholas B. Davies, An Introduction to Behavioural Ecology (3d ed., Wiley Blackwell, 1993).

${ }^{16}$ Shane D. Johnson, How Do Offenders Choose Where to Offend? Perspectives from Animal Foraging, 19(2) Legal \& Criminological Psych. 193 (2014).

${ }^{17}$ Lallen T. Johnson and Jerry Ratcliffe, A Partial Test of the Impact of a Casino on Neighborhood Crime, 30 SECURITY J. 437 (2017).
} 
or other customers. ${ }^{18}$ In addition, the consumption of free alcohol may serve to reduce the vigilance and increase the vulnerability of potential victims, thereby raising their suitability as potential targets.

Second, the amounts of money held by, and circulating between, casino staff and patrons establishes suitable targets for acquisitive crimes or crimes of fidelity. Such money, typically in the form of tokens, is often highly visible, with table games displaying "chips" and bells, and lights and whistles often accompanying a "big win" on a slot machine. In turn, the visibility of money can facilitate an offender's assessment of the suitability of specific individuals as crime targets. ${ }^{19}$

Third, the characteristics of gambling clientele could have criminogenic consequences. As Johnson and Ratcliffe ${ }^{20}$ note:

Individuals with low self-control may be less judicious in their playing decisions and as a result more likely to find themselves in compromised economic situations. In turn, casinos may be attractive places to those with low self-control because they encourage risk-taking behaviours, a characteristic found to be associated with criminal behaviour. ${ }^{21}$ Such individuals may engage in criminal activity to compensate for their losses.

Consequently, it would be reasonable to assume that an increase in suitable targets, coupled with a lack of capable guardians, may result in (increases in) crime in and around their vicinity. In response, a host of research studies ${ }^{22}$ have sought to establish whether or not casinos impact crime rates, drawing on city and county level crime data. Although this work has drawn mixed findings, evidence does indicate that in the areas in which crime did increase, this was the product of increased tourist and traffic levels as opposed to the introduction of a casino itself. ${ }^{23}$ Nevertheless, available evidence does reaffirm the theory that casinos can serve to increase the availability of suitable targets of crime and, in turn, the incidence of crime.

By comparison, research exploring the interrelationships between crime and gambling establishments in the UK remains limited. This is despite LBOs and other gambling premises bearing a number of features that make them conducive to violence and/ or acquisitive crime. For example, gamblers may take out anger on their losses towards staff or other customers, ${ }^{24}$ or engage in situational or opportunistic crime to recoup their losses. ${ }^{25}$ Indeed, the constant handling of cash would serve to make such an establishment a particularly attractive target for would-be offenders. ${ }^{26}$ In turn, such establishments may be considered to represent potential crime "hotspots,"27 leading to a disproportionate number of crimes occurring in and around such locations. ${ }^{28}$

Previous research focusing on the retail sector has illustrated the importance of exploring - with a view to enhancing - security measures for commercial establishments that hold large cash sums yet adopt a business model whereby only a small number of staff are on duty at any one time. ${ }^{29}$ Such academic assessment may be considered particularly pertinent in the case of licensed betting establishments, as lone working in a cash-based enterprise can increase crime risk for staff and businesses. ${ }^{30}$ In turn, this article explores national and local newspaper reports of

\footnotetext{
${ }^{18}$ Mark D. Griffiths and Matt Hopkins, Betting Shop Violence: A Cause for Concern?, 74(1) POLICE J. 55 (2001).

${ }^{19}$ B. Grant Stitt, Mark Nichols, and David Giacopassi, Does the Presence of Casinos Increase Crime? An Examination of Casino and Control Communities, 49(2) Crime \& Delinquency 253 (2003).

${ }^{20}$ Johnson and Ratcliffe, supra note 17, at 5.

${ }^{21}$ Michael Gottrredson and Travis Hirschi, A General Theory of Crime (Stanford University Press, 1990)

${ }^{22}$ Jay Albanese, The Effect of Casino Gambling on Crime, 48(2) Fed. Probation 39 (1985); Stitt, Nichols, and Giacopassi, supra note 19; Earl L. Grinols and David. B Mustard, Casinos, Crime, and Community Costs, 88(1) Rev. Econ. \& Stat. 28 (2006); Johnson and Ratcliffe, supra note 17

${ }^{23}$ BANKS, supra note 12 .

${ }^{24}$ Mark D. Griffiths, Adrian Parke, and Johnathan Parke, Gambling-Related Violence: An Issue for the Police?, 78(3) PoLICE J. 223 (2005).
}

\footnotetext{
${ }^{25}$ Stitt, Nichols, and Giacopassi, supra note 19

${ }^{26}$ Griffiths and Hopkins, supra note 18 .

${ }^{27}$ Lawrence Sherman, Patrick Gartin, and Michael Buerger, Hot Spots of Predatory Crime: Routine Activities and the Criminology of Place, 27(1) CRIMINOLOGY 27 (1989).

${ }^{28}$ Shane D. Johnson and Kate J. Bowers, The Stability of Space-Time Clusters of Burglary, 44(1) Brit. J. Criminology 55 (2004); Jerry H. Ratcliffe and George F. Rengert, Near-Repeat Patterns in Philadelphia Shootings, 21 Security J. 58 (2008).

${ }^{29}$ Home Office, Standing Conference on Crime Prevention, Report of the Working Group on Commercial Robbery (Home Office Crime Prevention Unit, 1986); Claire Austin, The Prevention of Robbery at Building Society Branches (Home Office Crime Prevention Unit, 1988).

${ }^{30}$ Randeep Ramesh, Betting Shops Odds-On Favourites to Be Targeted by Robbers, Police Warn, The Guardian (July 22, 2016), https://www.theguardian.com/uknews/2016/jul/22/betting-shops-serious-crime-robbery-metropolitan-police-flyingsquad.
} 
betting shop robberies, giving consideration to the nature of offending, the presence of capable guardians, and the implications for worker safety.

\section{METHODOLOGICAL APPROACH}

This article examines the characteristics of betting shop robberies through a content analysis of national and local newspaper reports. We are mindful of the partial picture media reporting of offending provides, as news stories often focus on atypical rather than typical crime events. ${ }^{31}$ Nevertheless, given the paucity of official data relating to gambling-related crime in the UK, we suggest that our approach offers an original empirical contribution to understanding how operators may better protect their workers, by providing some insight into the characteristics of betting shop robberies.

In generating a news sample for analysis we undertook a systematic search of the Nexis database. Our initial sample was drawn from a two-year period between January 1, 2016 and December 31, 2017. Headlines, lead paragraphs and the remainder of news articles were searched using a combination of terms, including "bookies," "betting shop," "betting office," "bookmakers," "robbery," "armed robbery," "theft," and "crime." Whilst it is certainly possible that some stories were not identified through the use of such terms it is highly unlikely that many news articles would not have employed this language. ${ }^{32}$ Following our initial search of the Nexis database, a second manual sift was undertaken, with a view to refining the sample by removing duplicate stories and any irrelevant news reports. Upon completion, our final sample comprised 228 articles.

Once the units of analysis were detected, categories were designed and operationalized, in order to summarize and describe the content. News articles were coded according to content, with quantifiable data recorded in an excel spreadsheet. This included: the date of the newspaper article; the newspaper titles; the category of the offence reported; the LBO operator; the location of the LBO; the time and day of the offense; details of the offense and the offender; and the number of staff working at the LBO. Thus, we recorded features that were both present and absent in the newspaper reports under analysis. The purpose of the content analysis was to identify constituents of betting shop robberies that might merit a more interpretative analysis.

\section{RESULTS}

A total of 241 crimes were reported across the 228 national and local newspaper articles that constitute the sample for this study. Table 1 summarizes the newspaper reports of crimes at LBOs.

Newspaper articles reported on 212 robberies and 26 attempted robberies, as well as one charge of theft and one charge of going equipped for theft and the possession of a knife. Such crimes were distributed across all the major LBO operators, with Betfred $(n=56)$, Coral $(n=52)$, Ladbrokes $(n=56)$, Paddy Power $(n=9)$, and William Hill $(n=26)$ victims of robberies and/ or attempted robberies. A number of smaller companies and independent operators $(n=19)$ were also victims of crime.

Figure 1 presents a temporal heat map designed to illustrate the temporal distribution of LBO offenses. The temporal distribution of offenses was recorded by day and hour, with a value of "1" given to each day/hour slot in which an offense was known to have taken place. Once all weightings had been calculated, a heat map was created using the Microsoft Excel "Conditional Formatting" function, using a three-color scale allocated to the maximum, 50th percentile, and minimum values. This approach has been used in prior criminological research to explore crime incidence. ${ }^{33}$ To help overcome instances with incomplete temporal data, a process of aoristic analysis was employed, which enables users to establish a probability estimate that an offense took place within given temporal parameters. Using this approach, probabilities are assigned to produce a "weight" for each time parameter (i.e., each hour) in which an offense may have taken place, with weights assigned proportionately to the number/proportions of
${ }^{31}$ Yvonne JewKes, Media And Crime (3d ed., Sage, 2014).

${ }^{32}$ Paul Mason, Lies, Distortion and What Doesn't Work: Monitoring Prison Stories in the British Media, 2(3) Crime, Media, Culture 251 (2006).
${ }^{33}$ Dan Jerome S. Barrera, Bomb Threats and Reports of Suspicious Items in the Philippines: Spatial and Temporal Patterns, 30(3) SECURITY J. 665 (2017). 
Table 1. Summary of Newspaper Reports of Crimes at Licensed Betting Offices

\begin{tabular}{|c|c|c|}
\hline & $n$ & $\%$ \\
\hline Total number of crimes & 241 & 100 \\
\hline \multicolumn{3}{|l|}{ Offense } \\
\hline Robbery & 212 & 88 \\
\hline Attempted robbery & 26 & 11 \\
\hline Other & 2 & 1 \\
\hline \multicolumn{3}{|l|}{ Operator $^{1}$} \\
\hline Betfred & 56 & 23 \\
\hline Coral & 52 & 22 \\
\hline Ladbrokes & 56 & 23 \\
\hline Paddy Power & 9 & 7 \\
\hline William Hill & 26 & 11 \\
\hline Other betting office & 19 & 8 \\
\hline Unnamed betting office & 23 & 10 \\
\hline \multicolumn{3}{|l|}{ Day of the week } \\
\hline Monday & 33 & 14 \\
\hline Tuesday & 41 & 17 \\
\hline Wednesday & 24 & 10 \\
\hline Thursday & 32 & 13 \\
\hline Friday & 17 & 7 \\
\hline Saturday & 27 & 11 \\
\hline Sunday & 31 & 13 \\
\hline Not stated & 36 & 15 \\
\hline \multicolumn{3}{|l|}{ Time of offense } \\
\hline Before 12:00 p.m. & 26 & 11 \\
\hline 12:00 p.m.-5:00 p.m. & 33 & 14 \\
\hline After 5:00 p.m. & 112 & 46 \\
\hline Not stated & 70 & 29 \\
\hline \multicolumn{3}{|l|}{ Number of offenders } \\
\hline One & 165 & 68 \\
\hline Two & 65 & 27 \\
\hline Three or more & 11 & 5 \\
\hline \multicolumn{3}{|l|}{ Weapon $^{2}$} \\
\hline Knife & 77 & 31 \\
\hline Firearm/imitation firearm & 88 & 35 \\
\hline Hammer & 9 & 4 \\
\hline Machete/meat cleaver/axe & 11 & 4 \\
\hline Metal bar & 7 & 3 \\
\hline Other & 25 & 10 \\
\hline No weapon mentioned & 31 & 13 \\
\hline \multicolumn{3}{|l|}{ Lone working ${ }^{3}$} \\
\hline Yes & 68 & 28 \\
\hline No & 73 & 30 \\
\hline Not stated/unclear & 100 & 41 \\
\hline
\end{tabular}

${ }^{1}$ Does not sum to 100 because of rounding errors.

${ }^{2}$ Totals 248 as some crimes involved more than one type of weapon.

${ }^{3}$ Does not sum to 100 because of rounding errors. hours between the possible "from" and "to" times. ${ }^{34}$ These proportionate weightings were only calculated in cases $(\mathrm{n}=8)$ where there was some indication as to the offense time; for example, morning (before 12:00 p.m.), afternoon (12:00-5:00 p.m.), or evening (5:00 p.m. onwards), and thus some degree of accuracy in the proportionate weightings given. However, there are a number of offenses for which no temporal details were provided $(\mathrm{n}=70)$. In such instances, it was decided not to employ aoristic analysis to calculate weighted probabilities, to avoid the potential emergence of Type 1 errors. This was because for these cases, weightings would be spread across the day (rather than cases where there was some temporal indication as to morning/afternoon/evening, etc.), and thus a build-up of (potentially) inaccurate estimated weightings over the course of the day may result in the weightings of individual hourly slots (and sections of the day) being falsely inflated.

Whilst evidence indicates no pattern in terms of the day of the week in which crimes took place, summary data does illustrate that offenses were more likely to occur in the evening (after 5:00 p.m.) than the morning (before 12:00 p.m.) or afternoon (12:00 p.m.-5:00 p.m.). Of the 248 crimes reported by newspapers, 46\% $(\mathrm{n}=112)$ took place after 5:00 p.m., 14\% $(\mathrm{n}=33)$ between 12:00 p.m. and 5:00 p.m., and $11 \%(\mathrm{n}=26)$ prior to $12: 00$ p.m. The time of the offense was not stated in $29 \%$ $(n=70)$ of the crimes reported by newspapers.

Crimes were often committed by a single offender, with $68 \%(n=165)$ committed by one individual, $27 \%(\mathrm{n}=65)$ by two people, and $5 \%$ by three or more individuals. The use or threat of violence was a notable feature of the robberies reported in the newspaper articles examined, with $87 \%(n=210)$ of crimes involving the use of some form of weapon. This included knives $(\mathrm{n}=77,31 \%)$; firearms and/or imitation firearms $(n=88,35 \%)$; hammers $(n=9$, $4 \%)$; machetes, meat cleavers, or axes $(n=11$, $4 \%)$; and metal bars $(\mathrm{n}=7,3 \%)$. Newspaper reports identified a number of other weapons $(\mathrm{n}=25,10 \%)$ such as corrosive liquids, baseball bats, broken bottles, tyre wrenches, and a taser as being used by offenders in the commission of robberies. 


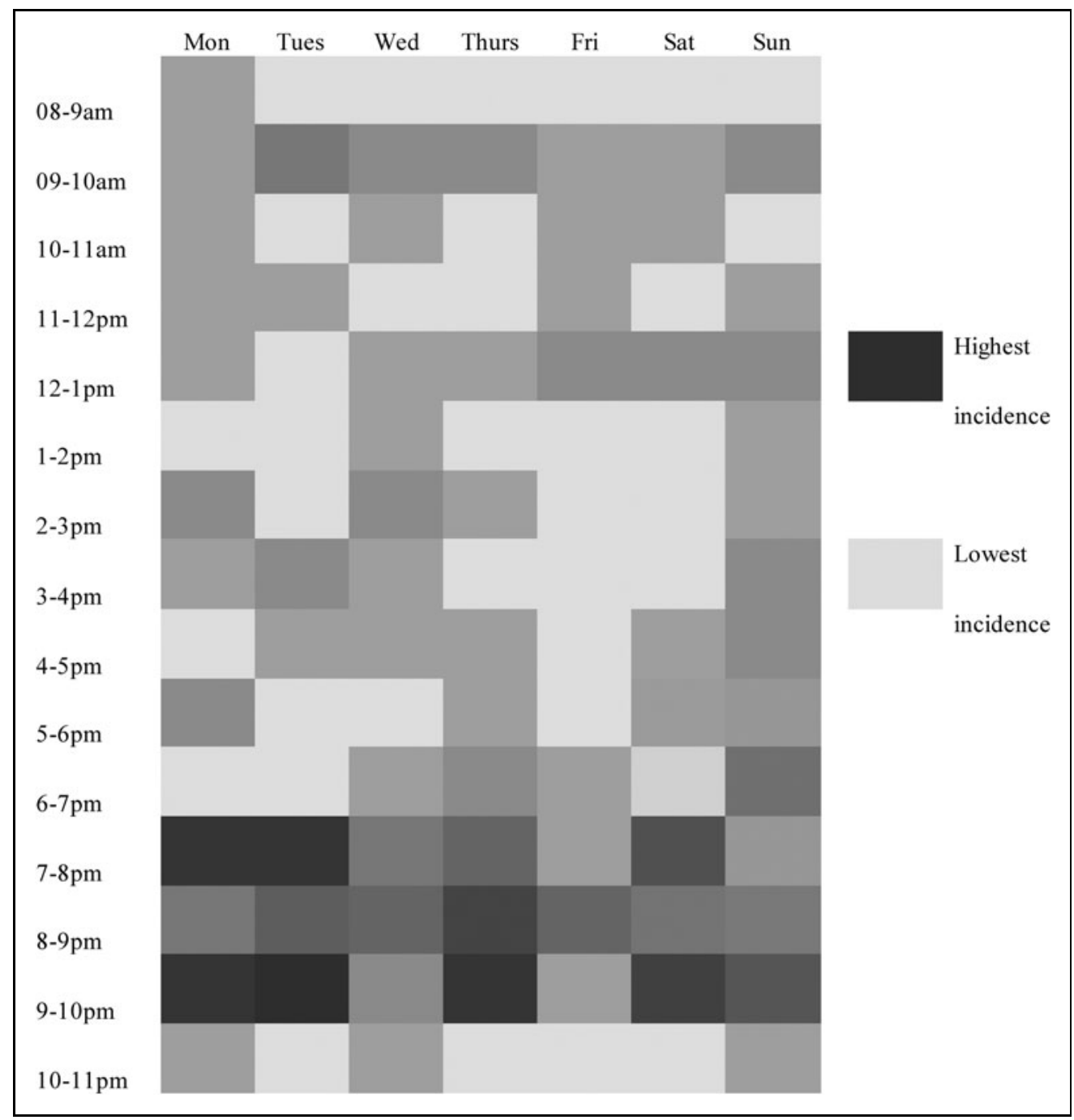

FIG. 1. Temporal distribution of licensed betting office offenses.

Although a substantial proportion of newspaper articles $(n=100,41 \%)$ did not state the number of staff working in the LBO at the time of the crime, $28 \%$ $(n=68)$ of reports indicate that offenses were committed when lone working was in operation, whilst $30 \%(n=73)$ of newspaper articles highlighted that there was more than one member of staff on the premises when the offense was committed.

\section{DISCUSSION}

Newspaper reports illustrate that LBOs are targets for acquisitive crimes, like most other retail and cashbased establishments. Evidence derived from this examination of the characteristics of robberies and attempted robberies reported in national and local newspapers enables consideration of how LBO operators may better guard against victimization and, in turn, better protect their workers and customers. This is necessary given that robberies of LBOs typically involve weapons, and the use and/or threats of violence.

To date, we know relatively little regarding the presence of violence in LBOs, because large-scale surveys of crime and victimization typically amalgamate betting shops with other retailers, obfuscating the extent and nature of violence and aggression that takes place in and around such locations. ${ }^{35}$ Where such data can be disaggregated, available evidence 
indicates that rates of violence and aggression are low. For example, Tilley and Hopkins ${ }^{36}$ explored the prevalence and nature of violence within UK retail environments through their Small Business and Crime Initiative survey and reported that there were, on average, 22 incidents of abuse, and 3.6 incidents of violence per 1,000 gambling establishments. In contrast, academic research ${ }^{37}$ indicates that aggression is prevalent in the UK gambling domain, with an average of seven incidents of aggression per hour, although much of this is verbal rather than physical in nature. Such a finding is reiterated in Cassidy's ethnographic research, ${ }^{38}$ which noted that low-level violence was a common occurrence in betting shops. However, most recently, police-derived data has pointed towards an upward trend in physical forms of violence at LBOs, with assaults and criminal damage in and around betting shops on the rise in London. ${ }^{39}$ Our research contributes to this knowledge base by illustrating that serious forms of violence can and do take place in LBOs.

As routine activity theory posits, and our data affirms, LBOs represent suitable targets for robberies that are typically violent in nature. The data presented in this article illustrates that although crimes were committed across LBOs' opening hours, many of the robberies took place in the evening when neighboring shops were closed and fewer people were present either in the shop or the surrounding vicinity. This reduction in suitable guardians increases the potential risk to LBOs, their staff, and customers. The risk of criminal victimization is likely to be greater in the darker winter months, as LBOs remain open until 10:00 p.m. in order to enable customers to place bets on a wide range of sporting events as they happen.

The potential rewards for offenders are also likely to be greater at such times, as shops may retain the day's takings. The accumulation of unmarked bank notes, primarily through FOBTs, means that LBOs repre- sent suitable targets for motivated offenders. Whilst our data demonstrates that a substantial proportion of offenses were committed in the evening, close to closing time, it also highlights that some robberies take place upon opening or when the previous day's earnings are being taken to the bank or post office by a member of the betting shop's staff.

The suitability of LBOs as a target for acquisitive crime is likely to be compounded further by the use of lone working, which occurred in at least $28 \%$ of reported robberies and almost half of all newspaper articles where the number of staff was stated. Lone working typically occurs in the evening, but also in the early morning, further reducing capable guardianship at LBOs at times when the number of people in and around betting shops are likely to be at their lowest and the rewards at their highest.

A number of policymaking implications are derived from the study's findings. Previous research ${ }^{40} \mathrm{dem}-$ onstrates how optimal forager theory can play a substantial role in crime prevention policy, and, in line with such thinking, we suggest that LBO operators can institute a series of measures that will reduce the reward for offenders, increase the time and effort necessary to commit the crime, and increase their risk of detection. This, in turn, will serve to reduce the risk to retail staff and customers of being victims of violent crime.

First, we would encourage LBO operators to abolish lone working, with a view to reducing the likelihood of robbery and the risk posed to retail staff. This may be considered essential given that our analysis of betting shop robberies indicates that where lone working was in evidence, it often involved female workers, including one woman who was pregnant, working late at night. Previous research ${ }^{41}$ that has explored the prevention of robberies at commercial premises, such as building societies, provides important lessons for the gambling sector. These studies highlight that
${ }^{36}$ Nick Tilley and Matt Hopkins, Business as Usual: An Evaluation of the Small Business and Crime Initiative (Police Research Series Paper 95, Home Office, 1998).

${ }^{37}$ Adrian Parke and Mark D. Griffiths, Aggressive Behavior in Slot Machine Gamblers: A Preliminary Observational Study, 95(1) Psych. Rep. 109 (2004); Adrian Parke and Mark D. Griffiths, Aggressive Behaviour in Adult Slot Machine Gamblers: A Qualitative Observational Study, 2(2) Int'L J. Mental Health \& Addiction 50 (2005); Adrian Parke and Mark D. Griffiths, Aggressive Behaviour in Adult Slot Machine Gamblers: An Interpretative Phenomenological Analysis, 15 (4) J. Cmty. \& Applied Soc. Psych. 255 (2005).

\footnotetext{
${ }^{38}$ Rebecca Cassidy, 'A Place for Men to Come and Do Their Thing': Constructing Masculinities in Betting Shops in London, 65(1) British J. SocIO. 170 (2014); Rebecca Cassidy, Horse versus Machine: Battles in the Betting Shop, 18(2) J. Royal Anthropological Inst. 266 (2014).

${ }^{39}$ George Greenwood, Violence in and around Betting Shops Rises in London, BBC News (July 12, 2017, https://www.bbc.co.uk/news/uk-england-london-40558938.

${ }^{40}$ Johnson, supra note 16.

${ }^{41}$ Home Office, supra note 29; Austin, supra note 29.
} 
increasing "guardianship" and the risk of detection of offenders are key factors in preventing retail crime. Most significantly for LBOs, previous research has demonstrated that greater numbers of "frontline" staff or the introduction of specialized security personnel into retail environments where there is only a small volume of staff can serve to reduce the occurrence of violent crime.

Second, we suggest that greater efforts should be made by LBO operators to minimize the potential reward available to offenders, as well as increasing the time and effort required by offenders to commit a criminal act, in line with optimal forager theory. For example, Clarke and McGrath ${ }^{42}$ found that cash control methods, such as using time-lock cash boxes, having a cash limit on withdrawals, and using safes with adjustable time locks helped to reduce the incidence of robberies in betting shops in Victoria, Australia. Given that some of the robberies identified in this study were committed when staff were either emptying FOBTs or taking money to be banked, there is clearly a need for LBO operators to explore safer strategies for the transit and banking of money that reduces the risk to retail staff.

Third, in accordance with RAT and optimal forager theory, we would advocate that operators assess the risk posed to each individual LBO and avail themselves of the available crime prevention hardware where necessary in order to protect retail staff. This should include the installation of panic alarms and adequate outside lighting, closed circuit television, and magnetic door locks as standard, if they are not already in place.

Finally, we would encourage LBO operators to collect, share, and utilize data on incidents of crime and disorder that take place in and around their premises, with a view to reducing crime and victimization risks to retail staff and patrons. To date, examination of crime problems that relate to gambling have, in many areas, been hampered by a lack of robust data sources, undermining the ability to instigate data-driven crime prevention measures. In turn, we acknowledge that the data we have derived from national and local newspaper articles represents only a partial account of the crime problems that may impact the betting sector. As such, there is a need to corroborate our findings through other data sources.

Ensuring that gambling is free from crime is an important regulatory objective in the UK and it is essential that LBOs take appropriate steps to minimize crime and victimization in and around their premises. Previous research ${ }^{43}$ has highlighted that bookmakers' duty of care to its customers may require to them to deal with intoxicated customers, illegal gambling, excessive and problem gambling, and selfexclusion. We suggest that this duty of care should extend to betting shop staff and that LBO operators need to ensure that they take all appropriate measures to mitigate the likelihood of and potential harm caused by betting shop robberies.

\section{CONCLUSION}

This article reports on the first research study to examine the characteristics of betting shop robberies with a view to reducing the risk to retail staff. Drawing on data from national and local newspaper reports over a two-year period it illustrates that robberies at LBOs are often violent in nature, involve weapons, and frequently take place just after opening or before closing time when lone working is most likely to take place. Utilizing environmental criminological theory, we suggest that LBO operators should seek to institute a series of crime prevention measures that will reduce the reward for offenders, increase the time and effort necessary to commit the crime, and increase their risk of detection. Most significantly, we encourage LBO operators to abolish lone working in order to reduce the risk of criminal victimization to their retail staff.
${ }^{42}$ Ronald V. Clarke and Gerry McGrath, Cash Reduction and Robbery Prevention in Australian Betting Shops, 1 SeCURITY J. 160 (1990).
${ }^{43}$ Graham Brooks and Paul Sparrow, Bookmakers and a Duty of Care: Customers Views in England, 32 J. Gambling Stud. 737 (2015). 